\title{
The SIOD disorder protein SMARCAL1 is an RPA-interacting protein involved in replication fork restart
}

\author{
Alberto Ciccia, ${ }^{1,4}$ Andrea L. Bredemeyer, ${ }^{1,4}$ Mathew E. Sowa ${ }^{2}$ Marie-Emilie Terret, ${ }^{3}$ \\ Prasad V. Jallepalli, ${ }^{3}$ J. Wade Harper, ${ }^{2}$ and Stephen J. Elledge ${ }^{1,5}$ \\ ${ }^{1}$ Howard Hughes Medical Institute and Department of Genetics, Harvard Medical School, Division of Genetics, Brigham and \\ Women's Hospital, Boston, Massachusetts 02115, USA; ${ }^{2}$ Department of Pathology, Harvard Medical School, Boston, \\ Massachusetts 02115, USA; ${ }^{3}$ Molecular Biology Program, Memorial Sloan-Kettering Cancer Center, New York, New York \\ 10065, USA
}

\begin{abstract}
The integrity of genomic DNA is continuously challenged by the presence of DNA base lesions or DNA strand breaks. Here we report the identification of a new DNA damage response protein, SMARCAL1 (SWI/SNF-related, matrix associated, actin-dependent regulator of chromatin, subfamily a-like 1), which is a member of the SNF2 family and is mutated in Schimke immunoosseous dysplasia (SIOD). We demonstrate that SMARCAL1 directly interacts with Replication protein A (RPA) and is recruited to sites of DNA damage in an RPA-dependent manner. SMARCAL1-depleted cells display sensitivity to DNA-damaging agents that induce replication fork collapse, and exhibit slower fork recovery and delayed entry into mitosis following S-phase arrest. Furthermore, SIOD patient fibroblasts reconstituted with SMARCAL1 exhibit faster cell cycle progression after S-phase arrest. Thus, the symptoms of SIOD may be caused, at least in part, by defects in the cellular response to DNA replication stress.
\end{abstract}

[Keywords: HARP; DNA replication; DNA double-strand breaks; DNA replication stress]

Supplemental material is available at http://www.genesdev.org.

Received June 15, 2009; revised version accepted August 31, 2009.

The maintenance of genomic integrity depends on the faithful duplication of DNA during DNA replication. In S phase, the formation of DNA lesions, such as DNA crosslinks, ultraviolet light (UV)-induced pyrimidine dimers, and alkylated DNA bases, can interfere with DNA replication by blocking the progression of replication forks (Tercero and Diffley 2001; Niedernhofer et al. 2005). In addition, single-strand breaks (SSBs), which can be generated by camptothecin (CPT), ionizing radiation (IR), or reactive oxygen species, can be converted to double-strand breaks (DSBs) during DNA replication, and therefore induce the collapse of the replication fork (Kuzminov 2001). Furthermore, the structure of chromatin itself can present a barrier to DNA replication (Groth et al. 2007).

The SNF2 family of DNA-dependent ATPases represent a diverse group of proteins that contain similar DEAD-box helicase-like domains, but do not have classical helicase activity (Durr et al. 2006). Several members of this family, such as INO80 and SWR1, are components of large chromatin remodeling complexes, while others,

\footnotetext{
${ }^{4}$ These authors contributed equally to this work.

${ }^{5}$ Corresponding author.

E-MAIL selledge@genetics.med.harvard.edu; FAX (617) 525-4500.

Article published online ahead of print. Article and publication date are online at http://www.genesdev.org/cgi/doi/10.1101/gad.1832309.
}

such as RAD5 and RAD54, translocate along DNA in smaller complexes or alone. Interestingly, many SNF2 family members are involved in the repair of damaged DNA or the normal progression of DNA replication. For example, INO80 and SNF2H are required for efficient replication fork progression and repair of DNA DSBs (Collins et al. 2002; Papamichos-Chronakis and Peterson 2008; Shimada et al. 2008; Vincent et al. 2008). Other members of the SNF2 family, such as CSB, SWR1, RAD54, and RAD5, have also been implicated in the repair of various types of DNA lesions (Flaus et al. 2006).

SMARCAL1 (SWI/SNF-related, matrix associated, actindependent regulator of chromatin, subfamily a-like 1), or HARP (HepA-related protein), is a distant SNF2 family member that is mutated in Schimke immunoosseous dysplasia (SIOD), a pleiotropic syndrome characterized by skeletal dysplasia, renal failure, T-cell immunodeficiency and, in approximately one-half of cases, microcephaly (Coleman et al. 2000; Boerkoel et al. 2002; Flaus et al. 2006; Deguchi et al. 2008). Characterization of many of the known SMARCAL1 mutations from SIOD patients revealed that a large number altered the ATPase activity of the protein, demonstrating that it is required for normal SMARCAL1 function (Elizondo et al. 2009). However, the role of SMARCAL1 in vivo has not been 
elucidated. Unlike many other members of the SNF2 family, the ATPase activity of SMARCAL1 is not stimulated efficiently by dsDNA, but rather by stem-loop and forked DNA structures, as well as DNA containing single-stranded-to-double-stranded transitions with a recessed 3'-hydroxyl group (Muthuswami et al. 2000). Additionally, SMARCAL1 was shown recently to have ATPdriven strand annealing activity, capable of binding to forked DNA in vitro and rewinding regions of Replication protein A (RPA)-bound ssDNA in a plasmid context (Yusufzai and Kadonaga 2008).

RPA is an essential heterotrimeric complex (RPA1, RPA2, and RPA3) that binds and stabilizes ssDNA regions generated during DNA replication, recombination, and repair (Wold 1997). We showed previously that RPA can direct the localization of two DNA damage repair regulatory factors to the sites of ssDNA, the ATR/ATRIP (Ataxia-telangiectasia mutated [ATM] and Rad3-related/ ATR-interacting protein) kinase and the Rad17-RFC2-5 complex, the latter of which is stimulated to load the PCNA-like 911 complex onto DNA to activate the DNA damage response (Ellison and Stillman 2003; Zou and Elledge 2003; Zou et al. 2003). Here we show that SMARCAL1 interacts directly with RPA and is recruited to sites of DSBs and stalled or collapsed replication forks in an RPA-dependent manner. Moreover, RNAi depletion of SMARCAL1 in human cells leads to sensitivity to agents that cause DSBs and replication fork collapse and to defects in replication fork restart and mitotic entry following replication stress or DNA damage. These results suggest that SMARCAL1 is a novel factor involved in the response to DNA replication stress.

\section{Results}

\section{SMARCAL1 is a novel RPA-interacting protein}

We previously identified a large group of substrates of the ATM and ATR DNA damage response kinases (Matsuoka et al. 2007). To further study some of these substrates, we performed proteomic analysis of their interactions in human cells. In the purification of two such proteins, RPA1 and ATRIP, we identified SMARCAL1 as an inter- acting factor. To verify this interaction, we performed SMARCAL1 coimmunoprecipitations in both untreated cells and cells that had been exposed to DNA-damaging agents. To this end, we transduced $293 \mathrm{~T}$ cells expressing the tet repressor with a retrovirus containing HA-tagged SMARCAL1 (HA-SMARCAL1) under the control of a tetresponsive promoter. Expression of HA-SMARCAL1 was induced by treatment with doxycycline for $18 \mathrm{~h}$ and HASMARCAL1 was then immunoprecipitated with an antiHA antibody from untreated cells or from cells that had been exposed to $30 \mathrm{~J} / \mathrm{m}^{2} \mathrm{UV}$ or $10 \mathrm{~Gy}$ IR. The proteins that coimmunoprecipitated with HA-SMARCAL1 were identified using tandem mass spectrometry. This analysis revealed that HA-SMARCAL1 interacts strongly with the RPA complex, verifying its initial identification, and this association was confirmed by Western blot (Fig. 1A). Interestingly, the ratio of RPA1:SMARCAL1 peptides identified by mass spectrometry in the HA-RPA1 immunoprecipitations was $\sim 10: 1$, while the ratio in the HASMARCAL1 immunoprecipitations was $\sim 1: 1$ (Supplemental Table 1). This suggests that most, if not all, SMARCAL1 is constitutively associated with RPA, and that this represents a small fraction of the total RPA in the cell. This result is not surprising, as RPA is known to have many interacting partners, but does suggest that the interaction with RPA may be critical for SMARCAL1 function. The only other known RPA-interacting protein that was also identified in the SMARCAL1 immunoprecipitation was WRN, suggesting that WRN and SMARCAL1 can both interact with RPA in a single complex (Supplemental Table 1). Coimmunoprecipitation of HA-RPA1 and endogenous SMARCAL1 was also confirmed by Western blot (Fig. 1A), as was the interaction between endogenous SMARCAL1 and RPA (Fig. 1B,C). The interaction between SMARCAL1 and RPA did not appear to be significantly affected by the presence of DNA damage, as the proteins coimmunoprecipitated equivalently in untreated cells and cells that had been treated with DNA-damaging agents (Fig. 1A). Similar results were obtained when HA-SMARCAL1 was immunoprecipitated from human foreskin BJ fibroblasts with or without IR treatment, indicating that the constitutive association between RPA and SMARCAL1 in 293T cells
A

Figure 1. Interaction between SMARCAL1 and RPA in human cell lines. (A) Input cell lysates and HA immunoprecipitates from 293T-Rex cells expressing control HA vector, HA-RPA1, or HA-SMARCAL1 were immunoblotted with antibodies to HA, SMARCAL1, RPA1, and RPA2. Cells were treated with 10 Gy IR or $30 \mathrm{~J} / \mathrm{m}^{2}$ UV or left untreated. (B) Protein complexes immunoprecipitated with IgG or anti-SMARCAL1 antibodies from 293T-Rex were analyzed for SMARCAL1 and RPA2 by Western blotting. $(C)$ Protein complexes immunoprecipitated from 293T-Rex cells with IgG or anti-RPA2 antibodies were immunoblotted with antibodies to SMARCAL1, RPA1, and RPA2.

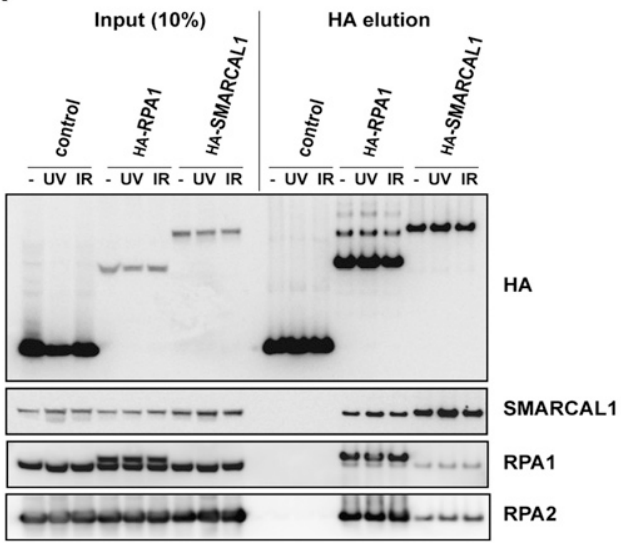

B

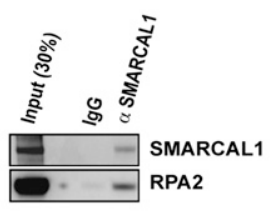

C

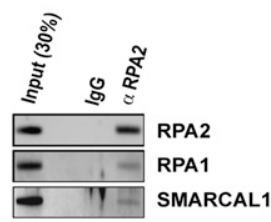


is not simply caused by high levels of replication stress due to their rapid proliferation (data not shown). While we were able to detect SMARCAL1 in the ATRIP immunoprecipitation, the reciprocal immunoprecipitation did not identify ATRIP and remains to be verified (data not shown).

\section{SMARCAL1 directly interacts with RPA2}

To determine whether the interaction between RPA and SMARCAL1 was direct, we expressed untagged RPA1, RPA2, RPA3, or His-tagged SMARCAL1 (HIS-SMARCAL1) in Escherichia coli (Fig. 2A). HIS-SMARCAL1 was pulled down with nickel beads and then mixed with lysates from E. coli expressing RPA1, RPA2, or RPA3. We efficiently precipitated RPA2 with HIS-SMARCAL1, but did not precipitate RPA1 or RPA3, demonstrating that SMARCAL1 interacts directly with the RPA complex through RPA2 (Fig. 2A). Alignment of SMARCAL1 with previously identified RPA2 interaction motifs from TIPIN, XPA, UNG2, and RAD52 revealed significant homology between these binding sites and the first 30 amino acids of SMARCAL1 (Fig. 2B; Mer et al. 2000; Unsal-Kacmaz et al. 2007). To confirm that this motif is required for interaction between SMARCAL1 and RPA2, we generated two SMARCAL1 mutants, RQK and $\Delta \mathrm{N}$ (Fig. 2B). The RQK mutant changes three conserved residues-previously defined as being critical for interaction between RPA2 and RAD52, XPA, and UNG2-to alanine (Mer et al. 2000). The $\Delta N$ mutant removes the first 30 residues of SMARCAL1, deleting the entire putative interaction site. Both of these mutants and wild-type SMARCAL1 were expressed in E. coli as His-tagged proteins, then bound to nickel beads and mixed with lysates from $E$. coli expressing all three RPA subunits. While the RPA trimer coimunoprecipitated with wild-type HIS-SMARCAL1, RPA did not efficiently coimmunoprecipitate with either the RQK or $\Delta \mathrm{N}$ mutants, although the RQK mutant showed residual binding to RPA (Fig. 2C). Similar results were obtained when wild-type and mutant His-tagged SMARCAL1 proteins were incubated with bacterial lysates containing only RPA2 (data not shown). Additionally, RPA2 did not efficiently coimmunoprecipitate with the HA-tagged RQK and $\Delta \mathrm{N}$ mutants when they were expressed in 293T cells (Fig. 2D); mass spectrometry revealed RPA1: SMARCAL1 peptide ratios of 1:5 and 1:12 in the RQK and $\Delta \mathrm{N}$ mutant immunoprecipitations, respectively (Supplemental Table 1). Thus, the $\mathrm{N}$ terminus of SMARCAL1 interacts specifically with RPA2, and this domain is required for the interaction between SMARCAL1 and the RPA trimer.
A

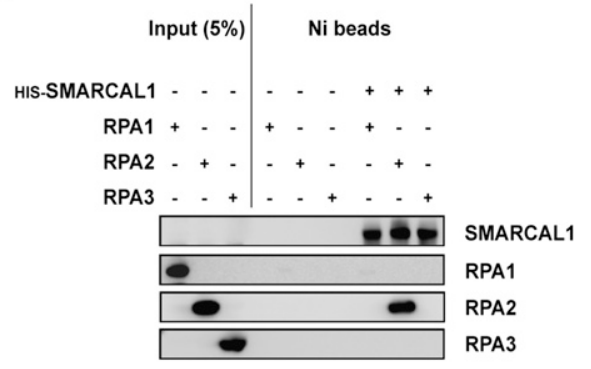

C

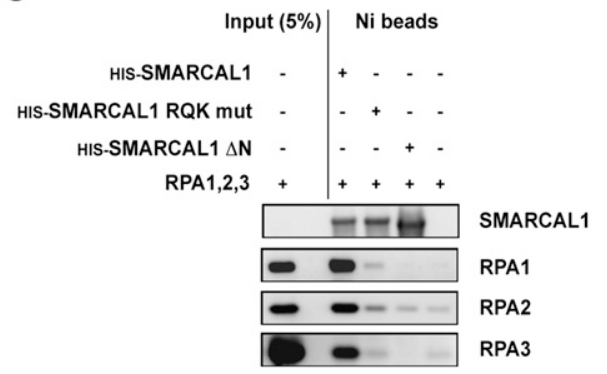

B

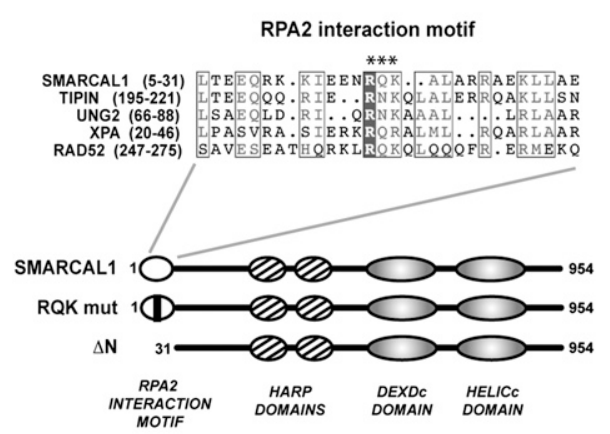

D

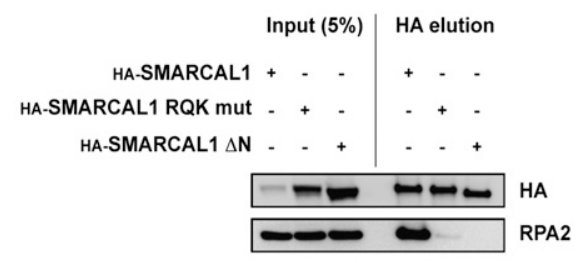

Figure 2. In vitro interaction between SMARCAL1 and RPA. (A) Western blot of protein complexes pulled down with nickel beads from BL21 (DE3) bacteria expressing untagged RPA1, RPA2, or RPA3, with or without His-tagged SMARCAL1. (B) Sequence alignment of the putative RPA2-interacting motif of SMARCAL1 with the previously known RPA2-interacting motifs of TIPIN, UNG2, XPA, and RAD52. Similar residues are indicated within boxes. Sequence alignments were performed with ClustalW. The schematic representation of human SMARCAL1 and the RQK and $\triangle \mathrm{N}$ mutants is shown below the sequence alignments. The amino acids mutated to alanine in the RQK mutant are indicated by asterisks. $(C)$ Western blot of protein complexes pulled down from bacteria coexpressing RPA1, RPA2, and RPA3 with nickel beads in the presence of either wild-type, RQK, or $\triangle N$ His-tagged SMARCAL1. (D) HA immunoprecipitates from 293T-Rex cells expressing wild-type, RQK, or $\triangle$ N HA-SMARCAL1 were immunoblotted with antibodies to HA and RPA2. 
Ciccia et al.

\section{SMARCAL1 is recruited to sites of DNA damage in an RPA-dependent manner}

The interaction between SMARCAL1 and the RPA complex, which binds ssDNA during both DNA replication and repair of various DNA lesions, suggested that SMARCAL1 may also function during these processes. To determine if SMARCAL1 localizes to sites of DNA damage, we retrovirally expressed an N-terminal GFPSMARCAL1 fusion protein in U2OS cells and assayed for its recruitment to DNA lesions caused by various DNAdamaging agents. Treatment of cells with hydroxyurea (HU) generates stalled replication forks and leads to formation of repair foci that include RPA and $\gamma-\mathrm{H} 2 \mathrm{AX}$. Cells expressing GFP-SMARCAL1 were treated with 2 $\mathrm{mM}$ HU for $12 \mathrm{~h}$ to induce replication fork stalling. We found that GFP-SMARCAL1 was recruited to foci in the HU-treated cells, and colocalized at these foci with RPA (Fig. 3A). Similarly, GFP-SMARCAL1 was recruited to foci generated in cells treated with the topoisomerase I inhibitor CPT, which causes DNA DSBs when replication forks encounter the stabilized topoisomerase I-DNA complex (Fig. 3A).

Microirradiation of cells with a UV-A laser following incorporation of BrdU into DNA causes photolysis of BrdU, which generates DNA DSBs at the sites of laser irradiation. We used laser microirradiation of BrdUtreated U2OS cells expressing GFP-SMARCAL1 to de- termine if SMARCAL1 is also recruited to these sites of DNA damage. Indeed, we found that GFP-SMARCAL1 was recruited to laser-generated stripes, where it colocalized with RPA2 and $\gamma$-H2AX (Fig. 3A,B). However, while $\gamma$-H2AX was generated in all cells that were microirradiated, SMARCAL1 was recruited to the laser-generated stripes in only $\sim 60 \%$ of cells (Fig. $3 \mathrm{C}$ ). This result was similar to what was observed for a GFP-RPA1 fusion protein, which is recruited to sites of DNA damage only during the S and G2 phases of the cell cycle, suggesting that SMARCAL1 is also recruited during these phases of the cell cycle (Fig. 3C). RPA recruitment to DSBs is restricted by the need for resection of the DNA ends by CtIP to generate ssDNA, which only occurs during $S$ and G2 (Sartori et al. 2007). To determine whether SMARCAL1 recruitment to DSBs is also restricted to resected ends, we transfected GFP-SMARCAL1 U2OS cells with siRNA against CtIP (Fig. 3D). While knockdown of CtIP did not affect generation of $\gamma-\mathrm{H} 2 \mathrm{AX}$ at sites of microirradiation, GFP-SMARCAL1 recruitment was reduced fourfold, which was similar to the reduction observed for GFP-RPA1, suggesting that SMARCAL1 is only recruited to DNA DSBs that have been processed to generate ssDNA (Fig. 3B,C).

Purified SMARCAL1 binds to specific DNA structures in vitro, but its association with RPA in vivo and its similar pattern of recruitment to sites of DNA damage
A

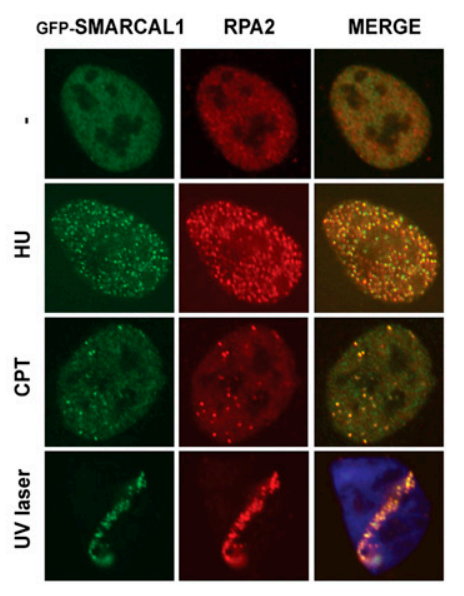

Figure 3. Colocalization of SMARCAL1 and RPA at DNA damage sites. (A) U2OS cells expressing GFP-SMARCAL1 were stained with anti-GFP (green) and anti-RPA2 (red) antibodies following treatment with $2 \mathrm{mM}$ $\mathrm{HU}, 10 \mathrm{nM} \mathrm{CPT}$, or microirradiation with UV laser. (B) GFP-SMARCAL1 U2OS cells transfected with control or CtIP siRNAs were stained with anti-GFP (green) and anti- $\gamma \mathrm{H} 2 \mathrm{AX}$ (red) antibodies following UV laser microirradiation. Merged images have DAPI staining (blue). (C) Percentage of control or CtIP siRNAtreated U2OS cells displaying GFP-SMARCAL1 or GFP-RPA1 stripes over the total number of cells with $\gamma \mathrm{H} 2 \mathrm{AX}$ stripes following UV laser microirradiation. The data represent the average of two independent experiments. $(D)$ Cell lysates from cells described in $C$ were immunoblotted for CtIP and GAPDH. (E) U2OS cells expressing wild-type and mutant GFPSMARCAL1 constructs were microirradiated with a UV laser and stained as in $B$.
B

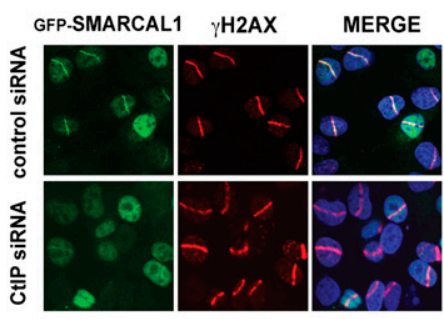

E

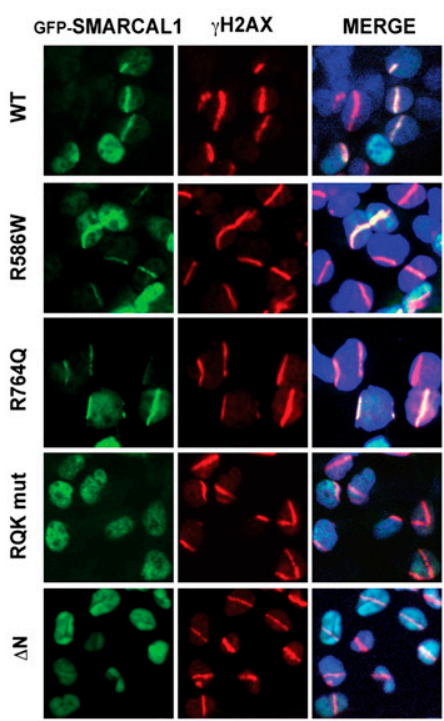


suggested that its interaction with RPA may be required for its localization in vivo. Thus, we transfected GFPSMARCAL1-expressing U2OS cells with siRNA against RPA2 and assayed GFP-SMARCAL1 recruitment to sites of damage during HU treatment. Indeed, we found that cells lacking RPA2 foci also lacked GFP-SMARCAL1 foci, while cells that retained RPA2 foci also had GFPSMARCAL1 foci (Supplemental Fig. 1A). Furthermore, the GFP-SMARCAL1 RQK and $\Delta \mathrm{N}$ mutants showed defective recruitment to both laser stripes and CPT foci (Fig. 3E; data not shown). In contrast, decreasing or abolishing the SMARCAL1 ATPase activity by introducing R586W and R764Q mutations, which are both found in SIOD patients, did not affect SMARCAL1 recruitment to sites of DNA damage (Fig. 3E). RPA localization is not dependent on expression of SMARCAL1, as U2OS cells depleted of SMARCAL1 using either siRNA or retrovirally expressed shRNAs showed normal generation of RPA foci in response to treatment with HU (Supplemental Fig. 1B; data not shown). Thus, interaction with RPA, but not ATPase activity, appears to be required for recruitment of SMARCAL1 to sites of DNA damage.

\section{Depletion of SMARCAL1 leads to DNA damage sensitivity}

Loss of proteins involved in the DNA damage response frequently leads to increased sensitivity to DNA-damaging agents. Thus, to verify that SMARCAL1 functions during the response to DNA damage, we used a cell competition assay (Smogorzewska et al. 2007) to determine the relative survival of cells with and without SMARCAL1 following treatment with several DNA-damaging agents. To this end, U2OS cells were infected with a retrovirus containing an shRNA targeting either SMARCAL1 or firefly luciferase (FF), then mixed equally with U2OS cells expressing dsRed. The mixed cells were treated with a DNA-damaging agent $\left(5 \mathrm{~Gy}\right.$ IR, $7 \mathrm{~J} / \mathrm{m}^{2} \mathrm{UV}, 150 \mathrm{nM}$ mitomycin C [MMC], or $10 \mathrm{nM} \mathrm{CPT)} \mathrm{or} \mathrm{left} \mathrm{untreated.}$ The relative sensitivity of the shRNA-expressing cells to the DNA-damaging agents was monitored $7 \mathrm{~d}$ later by flow cytometric analysis of the ratio of uncolored shRNA-expressing cells to $\mathrm{RFP}^{+}$cells. Compared with the control cells, the SMARCAL1 shRNA cells showed increased sensitivity to IR, MMC, and CPT, but not to UV (Fig. 4A). Similar results were obtained from depletion of SMARCAL1 using four individual siRNAs (Fig. 4B). SMARCAL1 levels were reduced to below the limit of detection by both shRNA and siRNAs (Fig. 4C,D). We also confirmed the sensitivity of the SMARCAL1 shRNA-expressing cells to IR using a traditional clonogenic survival assay, demonstrating that the loss of SMARCAL1-deficient cells following DNA damage is due primarily to decreased viability (Supplemental Fig. 2). These results suggest that SMARCAL1 is involved in the response to DNA DSBs and interstrand cross-links, but not the modified bases generated by exposure to UV.

The fact that SMARCAL1 is recruited to DNA DSBs through association with RPA, that RPA is required for homologous recombination, and that SMARCAL1 is re-
A

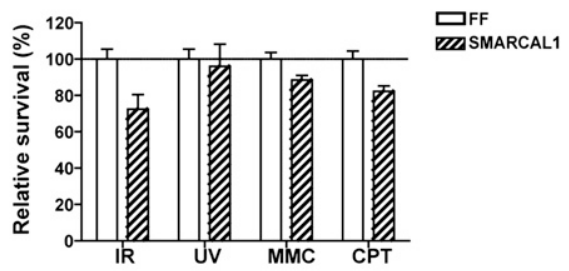

B

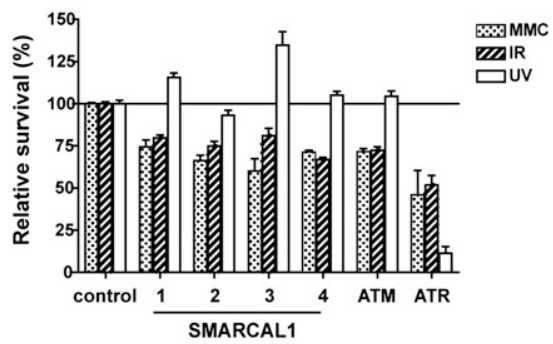

C

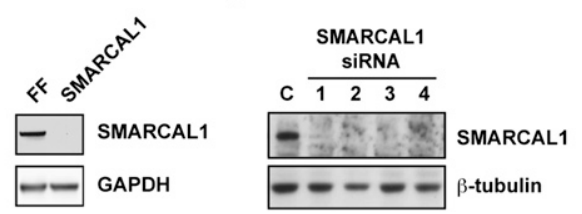

Figure 4. DNA damage sensitivity of SMARCAL1-depleted cells. (A) Cell competition assay showing survival of U2OS cells infected with SMARCAL1 shRNA or FF shRNA retroviruses, relative to dsRed-expressing U2OS cells, following treatment with DNA-damaging agents. (IR) 5 Gy IR; (UV) $7 \mathrm{~J} / \mathrm{m}^{2} \mathrm{UV}$; (MMC) 150 nM MMC; (CPT) 10 nM CPT. (B) Cell competition assay using siRNAs targeting SMARCAL1, ATM, or ATR, or a nontargeting control siRNA. Treatments are the same as described in $A$. $(C)$ Western blot showing depletion of SMARCAL1 in cells infected with retrovirus expressing SMARCAL1 shRNA. $(D)$ Western blot showing knockdown of SMARCAL1 in U2OS cells transfected with four individual SMARCAL1 siRNAs.

quired for resistance to agents that cause DSBs led us to examine whether SMARCAL1 was involved in homologous recombination. To this end, we depleted SMARCAL1 from U2OS cells containing the DR-GFP reporter that allows the detection of gene conversion events (Supplemental Fig. 3A; Pierce et al. 1999). This reporter contains two inactive copies of GFP, one of which has an I-SceI site within its coding region. Following cleavage with I-SceI, homologous recombination can be directed by the downstream inactive GFP, which generates a functional copy of GFP by gene conversion and allows for detection of cells that have undergone successful recombination by flow cytometry. After depletion of SMARCAL1 from DR-GFP U2OS cells, using four individual siRNAs, we infected the cells with adenovirus expressing I-SceI. DR-GFP U2OS cells transfected with a nontargeting siRNA had $15 \% \mathrm{GFP}^{+}$cells $48 \mathrm{~h}$ after infection with I-SceI virus, while only $2 \%$ of cells transfected with siRNA targeting CtIP, which is required for homologous recombination, were $\mathrm{GFP}^{+}$(Supplemental Fig. 3B). We found that three out of four siRNAs targeting SMARCAL1 had no effect on 
the percentage of $\mathrm{GFP}^{+}$cells generated after infection with I-SceI virus, while the fourth siRNA yielded a twofold decrease (Supplemental Fig. 3B). As all of the siRNAs knocked down expression of SMARCAL1 to a similar extent (data not shown), we conclude that SMARCAL1 is not required for efficient gene conversion.

\section{Cell cycle progression and replication restart following DNA damage are delayed in SMARCAL1-depleted cells}

SMARCAL1 ATPase activity has been shown in vitro to be stimulated by forked DNA structures and DNA molecules containing a double-stranded-single-stranded transition with a recessed $3^{\prime}$ end (Muthuswami et al. 2000). As similar structures are generated at replication forks, we investigated whether deficiency in SMARCAL1 affected DNA replication. Analysis of the cell cycle profile of SMARCAL1-depleted U2OS cells at steady state revealed no dramatic differences from control U2OS cells (Supplemental Fig. 4A). However, we did observe a defect in progression from $\mathrm{S}$ phase into mitosis when we followed BrdU-labeled cells over time (Fig. 5A; Supplemental Fig. 4B). In this experiment, S-phase cells were labeled with a 20-min pulse of BrdU, then monitored for accumulation in mitosis, as measured by phosphorylation of histone $\mathrm{H} 3$ Ser $10(\mathrm{P}-\mathrm{H} 3)$, in the presence of nocodazole to prevent exit of cells from mitosis. We found that, $10 \mathrm{~h}$ after BrdU labeling, the percentage of $\mathrm{BrdU}^{+}$cells that were also positive for $\mathrm{P}-\mathrm{H} 3$ was approximately twofold lower in SMARCAL1-depleted cells than in wild-type cells (Fig. 5A; Supplemental Fig. 4B). This delay in progression to mitosis was exacerbated by treatment with either $2 \mathrm{~Gy}$ IR or $5 \mathrm{nM}$ CPT. In this regard, we found that, in comparison with control FF U2OS cells, fourfold to fivefold fewer BrdU ${ }^{+}$SMARCAL1depleted U2OS cells were also $\mathrm{P}-\mathrm{H}^{+}{ }^{+} 10 \mathrm{~h}$ after IR (Fig. 5A). Similar results were observed for $\mathrm{BrdU}^{+} \mathrm{CPT}$-treated cells (Fig. 5A). Inhibition of DNA damage response kinases with caffeine abrogated the difference in $\mathrm{BrdU}^{+}$ $\mathrm{P}-\mathrm{H}^{+}$cells observed in IR- or CPT-treated cells (Fig. 5B). In agreement with the delayed progression from $S$ phase into mitosis of SMARCAL1-depleted U2OS cells, analysis of mitotic cells $10 \mathrm{~h}$ after release from thymidineinduced S-phase arrest into nocodazole revealed that fourfold fewer SMARCAL1-depleted cells had reached mitosis, as compared with control cells (Fig. 5C). Taken together, these results suggest that, although DNA replication is not detectibly perturbed by depletion of SMARCAL1, SMARCAL1-depleted cells in S phase are deficient in responding to DNA DSBs or to replication stress (which can also cause DSBs), leading to a delayed progression through G2 into mitosis that can be abrogated by inhibiting DNA damage checkpoints. Consistent with this conclusion, we see a slight but reproducible increase $(3 \%)$ in the G2 population of SMARCAL1-depleted cells compared with control cells (Supplemental Fig. 4A; data not shown).

As SMARCAL1 deficiency delays cell cycle progression after thymidine-induced S-phase arrest, we considered the possibility that SMARCAL1 could be required during the restart of stalled or collapsed replication forks. To assay the ability of SMARCAL1-deficient cells to restart DNA replication, SMARCAL1-depleted U2OS cells were arrested in $S$ phase with $2 \mathrm{mM}$ thymidine. Following release from the thymidine block, cells were pulsed with BrdU at various time points to measure the percentage of cells that had restarted DNA replication. Three hours after release from the thymidine block, approximately fourfold to fivefold fewer SMARCAL1-depleted cells had reinitiated DNA replication, as compared with wildtype cells (Fig. 6A). However, the same percentage of SMARCAL1-depleted and wild-type cells had reinitiated replication by $5 \mathrm{~h}$ following release from the thymidine block, indicating that reinitiation is delayed in the
A

Figure 5. Effects of SMARCAL1 depletion on cell cycle progression. (A) Analysis of FF control and SMARCAL1-depleted U2OS cells $10 \mathrm{~h}$ after a BrdU pulse alone (not treated, NT), or a BrdU pulse followed immediately by IR ( $2 \mathrm{~Gy}$ ) or addition of CPT ( $5 \mathrm{nM}$ ). Nocodazole was added after the BrdU pulse to capture mitotic cells, which are measured by staining for P-H3. Shown are the percentages of $\mathrm{BrdU}^{+}$cells that are also $\mathrm{P}-\mathrm{H} 3^{+}$. Values are means and standard deviations from at least two experiments. $P$-values were calculated using a one-tailed $t$-test. (B) Analysis of FF control and SMARCAL1-depleted U2OS cells $10 \mathrm{~h}$ after a BrdU pulse followed by 2 Gy IR or addition of $5 \mathrm{nM}$ CPT in the presence of $5 \mathrm{mM}$ caffeine. The analysis was performed as described in $A$. The numbers indicate the percentage of $\mathrm{BrdU}^{+} \mathrm{P}-\mathrm{H} 3^{+}$cells. $(C)$ Analysis of mitotic cells $\left(\mathrm{P}-\mathrm{H}^{+}{ }^{+}\right) 10 \mathrm{~h}$ after release from the thymidine block. Propidium iodide was used to measure DNA content. Numbers indicate the percentage of $\mathrm{P}-\mathrm{H} 3^{+}$cells.

B
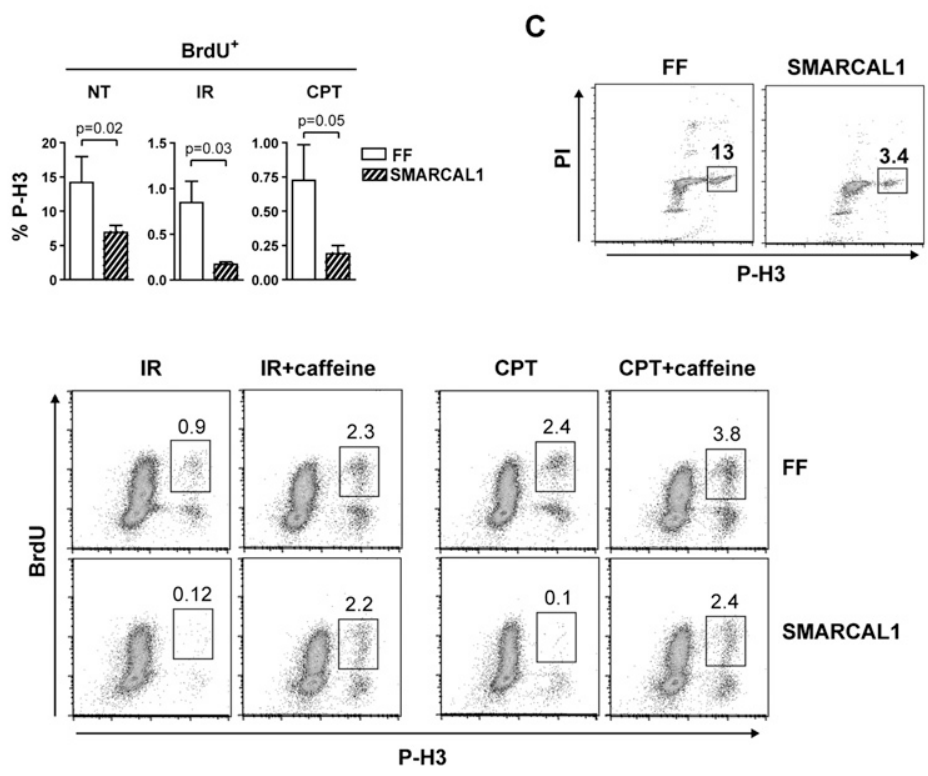
A

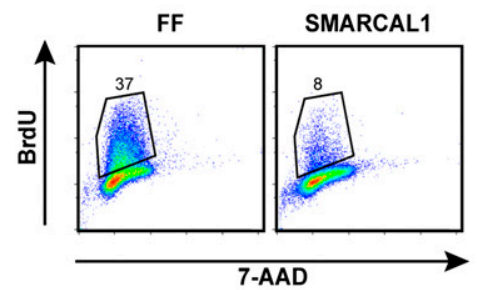

C

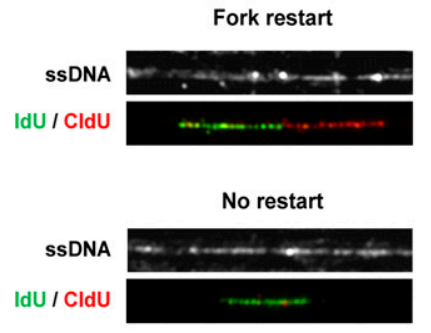

B

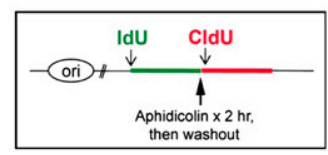

D

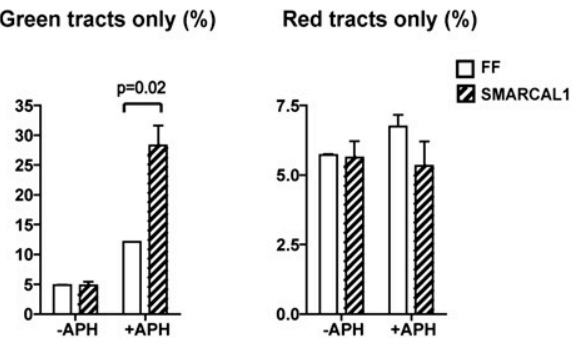

Figure 6. Effects of SMARCAL1 depletion on replication fork restart. $(A)$ Restart of DNA replication in FF control or SMARCAL1 shRNA-depleted U2OS was measured by incorporation of BrdU following release from the thymidine block. $\operatorname{BrdU}(10 \mu \mathrm{M})$ was added $30 \mathrm{~min}$ prior to fixation. 7-AAD was used to measure DNA content. The percentage of $\mathrm{BrdU}^{+}$ cells is indicated. Results are representative of three independent experiments. $(B)$ Schematics of the pulse-labeling experiment for DNA fiber analysis. (C) DNA fibers were stained with antibodies recognizing IdU (green) or CldU (red). AntissDNA antibody was used as a control. $(D)$ Analysis of the percentage of stalled or collapsed replication forks (green tracts only) in FF control or SMARCAL1 shRNA-depleted U2OS cells with or without aphidicolin treatment. The percentage of new origins fired during CldU treatment (red tracts only) is also shown. absence of SMARCAL1 but can eventually resume, although not necessarily from the same origins (data not shown). Similar results were obtained with two independent siRNAs targeting SMARCAL1 (data not shown).

To investigate replication restart more directly, we analyzed replication fork progression on single DNA fibers (Fig. 6B). Cells were pulse-labeled with the thymidine analog IdU, then treated with aphidicolin for $2 \mathrm{~h}$ to arrest replication forks. Following removal of aphidicolin, cells were labeled with another thymidine analog, CldU. Replication forks that were able to restart following aphidicolin treatment are visualized as a stretch of IdU incorporation (Fig. 6C, labeled in green) followed by a stretch of CldU incorporation (Fig. 6C, labeled in red). Tracts showing only IdU incorporation (Fig. 6C, green only) indicate stalled or collapsed forks that were unable to restart replication following removal of aphidicolin. Replication origins that fired after removal of aphidicolin show only CldU incorporation (Fig. 6C, red only). As suggested by the steady-state cell cycle analysis of SMARCAL1 shRNAexpressing U2OS cells, depletion of SMARCAL1 did not affect fork progression in the absence of DNA damage (Fig. 6D). However, the restart of replication forks following aphidicolin treatment was significantly decreased in the SMARCAL1-depleted cells, as indicated by the twofold to threefold increase in the percentage of tracts that showed only IdU incorportation (Fig. 6D). New origin firing after aphidicolin treatment, however, was not affected by SMARCAL1 depletion (Fig. 6D). Together, these data show that SMARCAL1 is involved in the restart of replication following DNA damage at the fork, due to either a role in preventing the irreversible collapse of stalled forks or a direct role in mediating the reinitiation of replication.

Finally, to better define the role of SMARCAL1 in a more pathologically relevant context, we expressed untagged SMARCAL1 in human telomerase reverse transcriptase
(hTERT)-immortalized fibroblasts derived from an SIOD patient (SD31) with mutations in the SMARCAL1 promoter that completely abrogate protein expression (Fig. 7A; Elizondo et al. 2009). SMARCAL1 reconstituted SD31 cells arrested in $2 \mathrm{mM}$ thymidine for $24 \mathrm{~h}$ were released into media containing BrdU. Three hours after release from the thymidine block, approximately twofold more SMARCAL1 reconstituted SD31 cells had reinitiated DNA replication, as monitored by BrdU incorporation (Fig. 7A). Moreover, SMARCAL1 reconstituted SD31 cells progressed more rapidly into mitosis, as we found that approximately twofold more reconstituted cells were $\mathrm{P}-\mathrm{H}^{+}{ }^{+} 15 \mathrm{~h}$ after thymidine release, as compared with the nonreconstituted cells (Fig. 7B). Reconstitution of SD31 cells with the R586W and R764Q SMARCAL1 mutants, which have defective ATPase activity, or with the $\Delta \mathrm{N}$ mutant, which lacks the RPA2-binding motif, did not lead to faster progression into mitosis following thymidine release (Figs. $7 \mathrm{~B}, \mathrm{C}$ ). Taken together, these results indicate that the ATPase activity and RPA binding of SMARCAL1 are critical for its in vivo function, and that SIOD might be at least partially caused by defective cell cycle progression following replication stress.

\section{Discussion}

In this study we showed that SMARCAL1 is important for replication fork restart, cell cycle progression, and the DNA damage response. SMARCAL1 is recruited to sites of DNA damage generated by both replication stress and microirradiation, and this recruitment is dependent on its interaction with the RPA complex. While SMARCAL1 was shown to facilitate removal of RPA from ssDNA during reannealing (Yusufzai and Kadonaga 2008), our results suggest that in vivo it exists in a previously assembled complex with RPA, which implies that it has roles beyond RPA removal. Moreover, S-phase cells depleted of 
Figure 7. Analysis of cell cycle progression in SIOD patient fibroblasts reconstituted with SMARCAL1. (A) DNA replication restart in hTERT-immortalized SIOD patient SD31 fibroblasts and SD31 fibroblasts reconstituted with untagged SMARCAL1 was measured by incorporation of BrdU $3 \mathrm{~h}$ after release from a thymidine block. Results are means and standard deviations of two independent experiments. $P$-value was calculated using a two-tailed $t$-test. $(B)$ Analysis of cell cycle progression in hTERT-immortalized SD31 fibroblasts and SD31 fibroblasts reconstituted with untagged wild-type or mutant SMARCAL1 constructs following a thymidine block. The graph shows the fold change in P-H3 ${ }^{+}$cells relative to nonreconstituted hTERT SD31 fibroblasts $15 \mathrm{~h}$ after release from a thymidine block into nocodazole. Values are means and standard deviations from at least two experiments. $\left({ }^{\star}\right) P=0.003$. The $P$-value was calculated using a two-tailed $t$-test. $(C)$ Western blot showing the expression of wild-type and mutant SMARCAL1 protein in the reconstituted hTERT-immortalized SD31 fibroblasts.

SMARCAL1 show sensitivity to DNA-damaging agents that generate DNA DSBs. Additionally, SMARCAL1deficient cells progress through late S/G2 more slowly than wild-type cells and exhibit delayed restart of DNA replication following replication stress or DNA damage. Consistent with these results, SMARCAL1 has been implicated in cellular proliferation, as mouse neurospheres depleted of SMARCAL1 exhibit defective growth (Deguchi et al. 2008). Together, our results suggest that SMARCAL1 functions at stalled or collapsed replication forks to promote their stability or to directly facilitate the restart of replication.

The previously described ssDNA annealing activity of SMARCAL1 suggests that its mechanism of action at replication forks is likely distinct from that of other SNF2 family members. SMARCAL1 may be important for limiting the amount of ssDNA generated at stalled replication forks or for regulating fork regression in a similar manner to bacterial RecG (Atkinson and McGlynn 2009). Additionally, SMARCAL1 may interact with other components of the replication and repair machinery, such as the WRN helicase, to facilitate its reassembly following repair of damaged forks. Interestingly, the helicases that are involved in replication restart in bacteria, PriA, RecG, and RecQ, are all constitutively associated with the bacterial RPA homolog SSB (Lecointe et al. 2007), as SMARCAL1 and WRN are associated with RPA. This association effectively anchors these proteins at sites of active DNA replication, as SSB is constitutively associated with ssDNA present at replication forks, thus allowing for efficient restart of replication in the event of fork stalling or collapse. We propose that the interaction of SMARCAL1 with RPA serves a similar purpose, concentrating SMARCAL1 at replication forks constitutively to allow for a rapid response when the fork stalls or collapses.

The observation that SMARCAL1-depleted cells are acutely sensitive to DNA-damaging agents that induce DSBs during $S$ phase-such as CPT, MMC, and IRindicates that SMARCAL1 could play a critical role in the restart of collapsed replication forks. The restart of a collapsed replication fork at a DSB requires DNA end resection and invasion of the $3^{\prime}$ ssDNA end into the homologous DNA duplex to form a D-loop structure, which serves as a template for resuming DNA synthesis (Heller and Marians 2006). This pathway, also known as break-induced replication (BIR), requires the re-establishment of DNA synthesis on both leading and lagging strands, whereas other homologous recombination pathways for DSB repair, such gene conversion, may involve leading but not lagging strand synthesis after strand invasion and D-loop formation (Wang et al. 2004; Llorente et al. 2008). Given that SMARCAL1 is important for the repair of collapsed forks and at the same time is dispensable for gene conversion, SMARCAL1 could have a specific role in the re-establishment and/or progression of lagging strand synthesis during the restart of collapsed forks, possibly by stabilizing D-loop structures or recruiting DNA replication factors, similar to phage T4 gp59 or bacterial PriA proteins (Jones and Nakai 2000). Interestingly, PriA has been shown to interact with recessed $3{ }^{\prime}$-OH DNA ends at ssDNA-to-dsDNA transitions, such as the termini of invading strands in D-loops and of stalled leading strands at replication forks, and to promote fork restart by loading the replicative helicase and DNA primase on the lagging strand (Heller and Marians 2006). As the interaction between SMARCAL1 and recessed 3'-OH ends has been shown to stimulate its ATPase activity in vitro (Hockensmith et al. 1986; Muthuswami et al. 2000), it may suggest that the activity of SMARCAL1 is stimulated by the same structures as PriA. Defining the mechanism of action of SMARCAL1 on these structures will likely be critical for understanding the pathogenesis of SIOD.

The role of SMARCAL1 in the DNA damage response uncovered here adds SMARCAL1 to the growing list of DNA damage response genes such as NBS1 (Nijmegen breakage syndrome), LIG4 (Ligase IV deficiency), ATR (Seckel syndrome), MCPH1/BRIT1 (Microcephaly 1), and others involved in microcephaly and mental retardation 
syndromes. Clearly, neural development is either excessively sensitive to the presence of DNA damage or experiences higher levels of spontaneous DNA damage and, therefore, requires maximal repair capacities relative to other tissues. Understanding which of these possibilities is responsible for these defects will have important implications for the treatment of patients suffering from these disorders.

\section{Materials and methods}

\section{Antibodies}

Rabbit polyclonal anti-RPA1 (1:100; Cell Signaling, \#2267), antiRPA2 (1:1000; Bethyl, A300-244A), and anti-SMARCAL1 (1:1000; gift from C. Boerkoel; Deguchi et al. 2008); goat polyclonal anti-CtIP (1:500; Santa Cruz Biotechnologies, sc5970); and mouse monoclonal anti-HA (1:1000; Covance, clone 16B12), anti-RPA3 (1:100; GeneTex, clone 1F4), and anti-SMARCAL1 (1:500; Abnova, clone B01) were used in Western blotting.

\section{DNA clones}

The Gateway entry vectors pDONR223-SMARCAL1 and pDONR223-RPA1 were purchased from Open Biosystems (clones no. OHS1770-97648815 and OHS1770-97651886, respectively). The Gateway entry vectors pDONR223-SMARCAL1-RQK and pDONR223-SMARCAL1- $\Delta \mathrm{N}$ were obtained from pDONR223SMARCAL1 by site-directed mutagenesis of the amino acid sequence RQK to AAA (amino acids 17-19 of SMARCAL1) or by deletion the first 30 amino acids of SMARCAL1, respectively. The bacterial expression vectors pCOLA-2-HIS-SMARCAL1, pCOLA2-HIS-SMARCAL1-RQK, and pCOLA-2-HIS-SMARCAL1- $\Delta \mathrm{N}$ were generated by Gateway recombination between pDON223SMARCAL1, pDON223-SMARCAL1-RQK or pDON223SMARCAL1- $\triangle \mathrm{N}$, and pCOLA-2 (Novagen). The pCDFDuetRPAl vector was generated by cloning RPAl into the NcoI and EcoRI sites of the pCDFDuet-1 vector (Novagen). The pCDFDuetRPA2 vector was generated by cloning RPA2 into the MfeI and XhoI sites of pCDFDuet-1, whereas pCDFDuet-RPA3 was obtained by cloning RPA3 in NdeI and BglII sites of pCDFDuet-1. The P11d-tRPA vector has been described previously (Henricksen et al. 1996). The mammalian expression vectors pMSCVGFP-SMARCAL1, pMSCV-GFP-SMARCAL1-RQK, pMSCVGFP-SMARCAL1- $\Delta$ N, pMSCV-GFP-RPA1, pMSCV-HA-SMARCAL1, and pMSCV-HA-RPA1 were generated by Gateway cloning between either pDONR223-SMARCAL1, pDONR223-SMARCAL1-RQK, pDONR223-SMARCAL1- $\triangle \mathrm{N}$ or pDONR223-RPA1, and pMSCVN-HA-Flag or pMSCV-N-EGFP. pMSCV-HA-SMARCAL1 and pMSCV-HA-RPAl contain a doxycycline-inducible promoter. pMSCV-SMARCAL1, pMSCV-SMARCAL1-RQK, and pMSCVSMARCAL1 $-\triangle \mathrm{N}$ were obtained by Gateway recombination between pDONR223-SMARCAL1, pDONR223-SMARCAL1RQK, pDONR223-SMARCAL1- $\Delta \mathrm{N}$, and pMSCV-C-EGFP, followed by the introduction of a stop codon at the end of the SMARCAL1 coding sequence. pMSCV-GFP-SMARCAL1-R586W, pMSCV-SMARCAL1-R586W, pMSCV-GFP-SMARCAL1-R764Q, and pMSCV-SMARCAL1-R764Q were obtained by site-directed mutagenesis of pMSCV-GFP-SMARCAL1 or pMSCV-SMARCAL1.

\section{Bacterial pull-downs}

E. coli BL21 (DE3) bacteria $(50 \mathrm{~mL})$ carrying either pCOLA-2HIS-SMARCAL1, pCOLA-2-HIS-SMARCAL1-RQK, pCOLA-2HIS-SMARCAL1- $\Delta \mathrm{N}$, pCDFDuet-RPA1, pCDFDuet-RPA2,
pCDFDuet-RPA3, or P11d-tRPA were grown at $30^{\circ} \mathrm{C}$ to $\mathrm{OD}_{600}=$ 0.3 and induced for $5 \mathrm{~h}$ with $0.1 \mathrm{mM}$ IPTG. Cell pellets were resuspended in $1.5 \mathrm{~mL}$ of lysis buffer $(50 \mathrm{mM}$ Tris at $\mathrm{pH} 7.5,500$ $\mathrm{mM} \mathrm{NaCl}, 10 \%$ glycerol, $0.5 \%$ Triton, $1 \mathrm{mM} \mathrm{DTT}, 10 \mathrm{mg} / \mathrm{mL}$ lysozyme) supplemented with protease inhibitors (Roche). Following sonication (twice at $30 \mathrm{sec}$ ), cell lysates were centrifuged at 14,000 rpm for $20 \mathrm{~min}$. Supernatants from bacteria expressing HIS-SMARCAL1, HIS-SMARCAL1-RQK, or HIS-SMARCAL1- $\Delta \mathrm{N}$ were then incubated for $2 \mathrm{~h}$ at $4^{\circ} \mathrm{C}$ with $25 \mu \mathrm{L}$ of Ni-NTA beads (Qiagen). Bead-bound proteins were then washed twice with lysis buffer and incubated for $1 \mathrm{~h}$ at $4^{\circ} \mathrm{C}$ with lysates from bacteria expressing either RPA1, RPA2, or RPA3 singly or the entire RPA trimer. Imidazole (20 $\mathrm{mM}$ final concentration) was added to the bacteria lysates to prevent aspecific protein binding. Protein complexes were then washed six times with lysis buffer, eluted in LDS sample buffer, and resolved on a Nupage Bis-Tris $4 \%-$ $12 \%$ gradient gel (Invitrogen).

\section{Protein purification and mass spectrometry}

Retroviruses generated from pMSCV-HA-SMARCAL1 or pMSCV-HA-RPA1 under control of a doxycycline-inducible promoter were transduced into 293T-Rex cells, which contain the tet repressor. Following selection of transduced 293T-Rex cell lines with $1 \mathrm{mg} / \mathrm{mL}$ puromycin and generation of stable cell lines, cDNA expression was induced by treating $4 \times 15-\mathrm{cm}$ plates of 293T-Rex stable cells for $24 \mathrm{~h}$ with $2 \mu \mathrm{g} / \mathrm{mL}$ doxycycline. 293T-Rex cells were then treated with DNA-damaging agents (10 Gy IR or $30 \mathrm{~J} / \mathrm{m}^{2} \mathrm{UV}$ ), or left untreated, and harvested for protein lysates in $1.5 \mathrm{~mL}$ of low-salt buffer $(50 \mathrm{mM}$ Tris at $\mathrm{pH}$ 7.5, $150 \mathrm{mM} \mathrm{NaCl}, 1 \% \mathrm{NP} 40$ ) supplemented with protease inhibitors (Roche) and phosphatase inhibitors cocktail set I and II (BD Pharmingen). Cell lysates were gently rocked for $1 \mathrm{~h}$ at $4^{\circ} \mathrm{C}$ and then centrifuged at 14,000 rpm for $25 \mathrm{~min}$. Cell pellets were then resuspended in high-salt buffer $(50 \mathrm{mM}$ Tris at pH 7.5, 500 $\mathrm{mM} \mathrm{NaCl}, 1 \% \mathrm{NP} 40$ ) and rocked for $1 \mathrm{~h}$ at $4^{\circ} \mathrm{C}$. After centrifugation, the high- and low-salt extracts were mixed together and the salt concentration was adjusted to $150 \mathrm{mM} \mathrm{NaCl}$. Protein complexes were then immunoprecipitated overnight using protein A beads coated with anti-HA antibody (Sigma), washed five times in low-salt buffer, and then eluted in $3 \times 50 \mu \mathrm{L}$ buffer with HA peptide $(500 \mu \mathrm{g} / \mathrm{mL}$; Sigma). The elution was TCAprecipitated and analyzed by tandem mass spectrometry using the CompPASS (Computational Proteomic Analysis Software Suite) platform as described previously (Sowa et al. 2009). Endogenous SMARCAL1 and RPA2 complexes were immunoprecipitated from 293T-Rex cell lysates prepared as described above using protein $\mathrm{G}$ beads (Co-IP kit, Pierce) cross-linked to SMARCAL1 (Bethyl, A301-616A) and RPA2 (Bethyl, A300-244A) antibodies $(3 \mu \mathrm{g})$. After five washes with low-salt buffer, protein were eluted from the beads with $3 \times 50 \mu \mathrm{L}$ of IgG elution buffer (Pierce) and were analyzed by Western blotting.

\section{Cell culture and RNAi}

The human embryonic kidney fibroblast cell line 293T was maintained in DMEM supplemented with $10 \%$ fetal bovine serum. The human osteosarcoma cell line U2OS was maintained in McCoy's medium supplemented with $10 \%$ fetal bovine serum. SD31 fibroblasts derived from an SIOD patient (gift from C. Boerkoel) were immortalized with a pWSL blasticidin retroviral vector expressing hTERT and maintained in DMEM containing Glutamax and $15 \%$ fetal bovine serum. hTERTimmortalized SD31 cells were transduced with the retroviral vectors pMSCV-SMARCAL1, pMSCV-SMARCAL1-RQK, pMSCV-SMARCAL1- $\Delta \mathrm{N}$, pMSCV-SMARCAL1-R586W, or 
pMSCV-SMARCAL1-R764Q and selected with $1 \mathrm{mg} / \mathrm{mL}$ puromycin for $48 \mathrm{~h}$ to obtain stable clones. The SMARCAL1 shRNA sequence (GAACTCATTGCAGTGTTTA) was embedded in a mir30 context in a pMSCV-PM vector. CtIP (catalog no. MQ011376-00), RPA2 (catalog no. MQ-017058-00), SMARCAL1 (catalog no. MQ-013058-01), and nontargeting siRNAs (catalog no. D-001206-14-05) were siGenome reagents purchased from Dharmacon. ATM (oligo nos. HSS181472, HSS181473, and HSS181474) and ATR (oligo nos. HSS182584, HSS182585, and HSS182586) siRNA were Stealth Select RNAi reagents purchased from Invitrogen. SMARCAL1 siRNAs were transfected individually, while CtIP, RPA2, ATM, ATR, and nontargeting siRNAs were transfected as a pool.

\section{Immunofluorescence}

The GFP-SMARCAL1 wild-type and mutant fusion proteins were detected using rabbit polyclonal anti-GFP antibody (1:1000; Invitrogen, A11122). $\gamma$-H2AX and RPA2 were detected using mouse monoclonal antibodies from Millipore (1:1000; clone JBW301) and Abcam (1:100; ab2175), respectively, and appropriate secondary antibodies conjugated with Alexa 488 or Alexa 594. For micorirradiation experiments, cells were treated with $10 \mu \mathrm{M}$ BrdU for $24 \mathrm{~h}$ prior to laser irradiation using a Zeiss Observer.Z1 inverted microscope with a Palm microbeam laser microdissection workstation. Following microirradiation, cells were incubated for $1 \mathrm{~h}$ at $37^{\circ} \mathrm{C}$, fixed with $4 \%$ formaldehyde, and permeabilized with $0.5 \%$ Triton-X. For foci experiments, cells were treated with $2 \mathrm{mM} \mathrm{HU}$ or $10 \mathrm{nM}$ CPT overnight, then analyzed as described above. Images were taken using an Olympus Fluoview confocal microscope.

\section{Cell competition assay}

Cell competition assays were carried out essentially as described previously (Smogorzewska et al. 2007). Briefly, U2OS cells expressing FF shRNA or SMARCAL1 shRNA were mixed in a 1:1 ratio with dsRed-expressing U2OS cells, then plated in triplicate. The following day, cells were exposed to $5 \mathrm{~Gy} \mathrm{IR,} 7 \mathrm{~J} / \mathrm{m}^{2}$ UV, or $10 \mathrm{nM} \mathrm{CPT}$, or left untreated. CPT was washed off the cells after $24 \mathrm{~h}$. After $7 \mathrm{~d}$, cells were analyzed on a BD LSRII flow cytometer. The ratio of colorless cells to dsRed ${ }^{+}$cells in the untreated population was set to $100 \%$, and the ratios observed in the treated populations were normalized to the untreated ratio. SMARCAL1-deficient cells were considered sensitive to a DNAdamaging agent when the percentage of colorless cells in the treated population, following normalization to the untreated population, was $<90 \%$ of the percentage observed in the FF population. Competition assays using siRNAs were carried out using a similar protocol, except that the siRNAs were transfected into U2OS cells expressing GFP and the competition was carried out against dsRed U2OS cells transfected with a pool of nontargeting siRNAs. Pools of ATM and ATR targeting siRNAs were used as controls.

\section{Clonogenic survival assay}

FF and SMARCAL1 shRNA-expressing U2OS cells were plated onto $10-\mathrm{cm}$ dishes at a concentration of 300 cells per dish. The following day, cells were treated with 0,2 , or 4 Gy IR. Two weeks later, the cells were stained with Coomasie blue and the number of colonies was counted. Each condition was analyzed in triplicate.

\section{Gene conversion analysis}

U2OS cells containing the DR-GFP gene conversion reporter (Pierce et al. 1999) were transfected with SMARCAL1, CtIP, or control siRNAs $48 \mathrm{~h}$ prior to infection with adenovirus expressing I-SceI restriction enzyme. The percentage of $\mathrm{GFP}^{+}$cells was analyzed by flow cytometry $72 \mathrm{~h}$ after adenoviral infection.

\section{Cell cycle progression and replication restart}

FF control or SMARCAL1 shRNA U2OS cells were labeled with BrdU for $20 \mathrm{~min}$, then washed and cultured in medium containing $100 \mathrm{ng} / \mathrm{mL}$ nocodazole. DNA-damaging agents (2 Gy IR or 5 $\mathrm{nM} \mathrm{CPT)} \mathrm{were} \mathrm{administered} \mathrm{immediately} \mathrm{following} \mathrm{BrdU} \mathrm{label-}$ ing, when appropriate. Mitotic cells were detected using an antibody against P-H3 (Millipore, clone 3H10) and Alexa 488conjugated antirabbit secondary. BrdU ${ }^{+}$cells and DNA content were detected using an APC BrdU Flow Kit (BD Pharmingen), according to the manufacturer's protocol. Alternatively, U2OS or hTERT-immortalized SD31 cells were cultured with $2 \mathrm{mM}$ thymidine for $18 \mathrm{~h}$ or $24 \mathrm{~h}$, respectively, to arrest them in S phase, then released into media containing nocodazole. Mitotic cells were detected as described above, but DNA content was detected with propidium iodide rather than 7-AAD. For analysis of restart of BrdU incorporation, U2OS or hTERT-immortalized SD31 cells released from thymidine block were incubated with $10 \mu \mathrm{M} \mathrm{BrdU}$ for $30 \mathrm{~min}$ or $1 \mathrm{~h}$, respectively, prior to harvesting at the indicated time points.

\section{Pulse-labeling of replication forks and DNA fiber analysis}

Exponentially growing cells were labeled with $50 \mathrm{mM}$ IdU for 20 $\mathrm{min}$, then $50 \mathrm{mM}$ CldU for $20 \mathrm{~min}$. Half of the samples were treated with $10 \mathrm{mM}$ aphidicolin for $2 \mathrm{~h}$ between the two pulses. Extended DNA fibers were prepared using a modification of the procedure described previously by Jackson and Pombo (1998). Briefly, labeled cells were trypsinized and resuspended in icecold PBS at $1 \times 10^{6}$ cells per milliliter. Two milliliters of this suspension were spotted onto a clean glass slide and lysed with $10 \mathrm{~mL}$ of spreading buffer $(0.5 \%$ SDS in $200 \mathrm{mM}$ Tris- $\mathrm{HCl}$ at $\mathrm{pH}$ 7.4, $50 \mathrm{mM}$ EDTA). After $6 \mathrm{~min}$, the slides were tilted at $15^{\circ}$ to horizontal, allowing the DNA to spread. Slides were air-dried, fixed in methanol and acetic acid (3:1) for $2 \mathrm{~min}$, and refrigerated overnight before immunolabeling. DNA was denatured with 2.5 $\mathrm{M} \mathrm{HCl}$ for $30 \mathrm{~min}$ at room temperature. Slides were rinsed three times in PBS and blocked in PBS + 0.1\% Triton X-100 (PBS-T) + $10 \%$ goat serum for $1 \mathrm{~h}$ at room temperature. Rat anti-BrdU (1:100; Abcam ab6326) and mouse anti-BrdU (1:100; Becton Dickinson 347580) were then applied to detect CldU and IdU, respectively. After a $1-\mathrm{h}$ incubation, slides were washed three times in PBS and stained with Alexa Fluor 488-labeled goat antimouse IgG1 antibody and Alexa Fluor 594-labeled goat anti-rat antibody (1:350 each; Invitrogen). Slides were mounted in Prolong Plus (Invitrogen) and held overnight at $4^{\circ} \mathrm{C}$. Replication tracks were imaged on a Nikon TE2000 microscope fitted with a $100 \times 1.4$ NA oil objective and measured using NIS Elements software. Continuity of DNA fibers was verified by staining with an anti-DNA antibody (1:300; Millipore MAB3034) and an appropriate secondary antibody (1:350; Alexa 647-labeled goat anti-mouse IgG2a [Invitrogen]).

\section{Acknowledgments}

We thank C. Boerkoel for kindly providing the SD31 patient cell line and a rabbit polyclonal SMARCAL1 antibody. A.C. is a recipient of an EMBO long-term fellowship. A.L.B. is supported by an NIH Institutional Training Grant. This work was supported by NIH grants to S.J.E., J.W.H., and P.V.J. S.J.E. is an investigator of the Howard Hughes Medical Institute. 


\section{References}

Atkinson J, McGlynn P. 2009. Replication fork reversal and the maintenance of genome stability. Nucleic Acids Res 37: 3475-3492.

Boerkoel CF, Takashima H, John J, Yan J, Stankiewicz P, Rosenbarker L, Andre JL, Bogdanovic R, Burguet A, Cockfield $S$, et al. 2002. Mutant chromatin remodeling protein SMARCAL1 causes Schimke immuno-osseous dysplasia. Nat Genet 30: 215-220.

Coleman MA, Eisen JA, Mohrenweiser HW. 2000. Cloning and characterization of HARP/SMARCAL1: A prokaryotic HepArelated SNF2 helicase protein from human and mouse. Genomics 65: 274-282.

Collins N, Poot RA, Kukimoto I, Garcia-Jimenez C, Dellaire G, Varga-Weisz PD. 2002. An ACF1-ISWI chromatin-remodeling complex is required for DNA replication through heterochromatin. Nat Genet 32: 627-632.

Deguchi K, Clewing JM, Elizondo LI, Hirano R, Huang C, Choi K, Sloan EA, Lucke T, Marwedel KM, Powell RD Jr, et al. 2008. Neurologic phenotype of Schimke immuno-osseous dysplasia and neurodevelopmental expression of SMARCAL1. I Neuropathol Exp Neurol 67: 565-577.

Durr H, Flaus A, Owen-Hughes T, Hopfner KP. 2006. Snf2 family ATPases and DExx box helicases: Differences and unifying concepts from high-resolution crystal structures. Nucleic Acids Res 34: 4160-4167.

Elizondo LI, Cho KS, Zhang W, Yan J, Huang C, Huang Y, Choi K, Sloan EA, Deguchi K, Lou S, et al. 2009. Schimke immuno-osseous dysplasia: SMARCAL1 loss-of-function and phenotypic correlation. J Med Genet 46: 49-59.

Ellison V, Stillman B. 2003. Biochemical characterization of DNA damage checkpoint complexes: Clamp loader and clamp complexes with specificity for 5 ' recessed DNA. PLOS Biol 1: E33. doi: 10.1371/journal.pbio.0000033.

Flaus A, Martin DM, Barton G), Owen-Hughes T. 2006. Identification of multiple distinct Snf2 subfamilies with conserved structural motifs. Nucleic Acids Res 34: 2887-2905.

Groth A, Rocha W, Verreault A, Almouzni G. 2007. Chromatin challenges during DNA replication and repair. Cell 128: 721-733.

Heller RC, Marians KJ. 2006. Replisome assembly and the direct restart of stalled replication forks. Nat Rev Mol Cell Biol 7: 932-943.

Henricksen LA, Carter T, Dutta A, Wold MS. 1996. Phosphorylation of human replication protein A by the DNAdependent protein kinase is involved in the modulation of DNA replication. Nucleic Acids Res 24: 3107-3112.

Hockensmith JW, Wahl AF, Kowalski S, Bambara RA. 1986. Purification of a calf thymus DNA-dependent adenosinetriphosphatase that prefers a primer-template junction effector. Biochemistry 25: 7812-7821.

Jackson DA, Pombo A. 1998. Replicon clusters are stable units of chromosome structure: Evidence that nuclear organization contributes to the efficient activation and propagation of S phase in human cells. J Cell Biol 140: 1285-1295.

Jones JM, Nakai H. 2000. PriA and phage T4 gp59: Factors that promote DNA replication on forked DNA substrates microreview. Mol Microbiol 36: 519-527.

Kuzminov A. 2001. Single-strand interruptions in replicating chromosomes cause double-strand breaks. Proc Natl Acad Sci 98: 8241-8246.

Lecointe F, Serena C, Velten M, Costes A, McGovern S, Meile JC, Errington J, Ehrlich SD, Noirot P, Polard P. 2007. Anticipating chromosomal replication fork arrest: SSB targets repair DNA helicases to active forks. EMBO J 26: 42394251.
Llorente B, Smith CE, Symington LS. 2008. Break-induced replication: What is it and what is it for? Cell Cycle 7: 859-864.

Matsuoka S, Ballif BA, Smogorzewska A, McDonald ER 3rd, Hurov KE, Luo J, Bakalarski CE, Zhao Z, Solimini N, Lerenthal Y, et al. 2007. ATM and ATR substrate analysis reveals extensive protein networks responsive to DNA damage. Science 316: 1160-1166.

Mer G, Bochkarev A, Gupta R, Bochkareva E, Frappier L, Ingles CJ, Edwards AM, Chazin WJ. 2000. Structural basis for the recognition of DNA repair proteins UNG2, XPA, and RAD52 by replication factor RPA. Cell 103: 449-456.

Muthuswami R, Truman PA, Mesner LD, Hockensmith JW. 2000. A eukaryotic SWI2/SNF2 domain, an exquisite detector of double-stranded to single-stranded DNA transition elements. I Biol Chem 275: 7648-7655.

Niedernhofer LJ, Lalai AS, Hoeijmakers JH. 2005. Fanconi anemia (cross)linked to DNA repair. Cell 123: 1191-1198.

Papamichos-Chronakis M, Peterson CL. 2008. The Ino80 chromatin-remodeling enzyme regulates replisome function and stability. Nat Struct Mol Biol 15: 338-345.

Pierce AJ, Johnson RD, Thompson LH, Jasin M. 1999. XRCC3 promotes homology-directed repair of DNA damage in mammalian cells. Genes \& Dev 13: 2633-2638.

Sartori AA, Lukas C, Coates J, Mistrik M, Fu S, Bartek J, Baer R, Lukas J, Jackson SP. 2007. Human CtIP promotes DNA end resection. Nature 450: 509-514.

Shimada K, Oma Y, Schleker T, Kugou K, Ohta K, Harata M, Gasser SM. 2008. Ino80 chromatin remodeling complex promotes recovery of stalled replication forks. Curr Biol 18: 566-575.

Smogorzewska A, Matsuoka S, Vinciguerra P, McDonald ER 3rd, Hurov KE, Luo J, Ballif BA, Gygi SP, Hofmann K, D'Andrea $\mathrm{AD}$, et al. 2007. Identification of the FANCI protein, a monoubiquitinated FANCD2 paralog required for DNA repair. Cell 129: 289-301.

Sowa ME, Bennett EJ, Gygi SP, Harper JW. 2009. Defining the human deubiquitinating enzyme interaction landscape. Cell 138: 389-403.

Tercero JA, Diffley JFX. 2001. Regularion of DNA replication fork progression through damaged DNA by Mec1/Rad53 checkpoint. Nature 412: 553-557.

Unsal-Kacmaz K, Chastain PD, Qu PP, Minoo P, Cordeiro-Stone M, Sancar A, Kaufmann WK. 2007. The human Tim/Tipin complex coordinates an Intra-S checkpoint response to UV that slows replication fork displacement. Mol Cell Biol 27: 3131-3142.

Vincent JA, Kwong TJ, Tsukiyama T. 2008. ATP-dependent chromatin remodeling shapes the DNA replication landscape. Nat Struct Mol Biol 15: 477-484.

Wang XA, Ira G, Tercero JA, Holmes AM, Diffley JFX, Haber JE. 2004. Role of DNA replication proteins in double-strand break-induced recombination in Saccharomyces cerevisiae. Mol Cell Biol 24: 6891-6899.

Wold MS. 1997. Replication protein A: A heterotrimeric, singlestranded DNA binding protein required for eukaryotic DNA metabolism. Annu Rev Biochem 66: 61-92.

Yusufzai T, Kadonaga JT. 2008. HARP is an ATP-driven annealing helicase. Science 322: 748-750.

Zou L, Elledge SJ. 2003. Sensing DNA damage through ATRIP recognition of RPA-ssDNA complexes. Science 300: 15421548.

Zou L, Liu D, Elledge SJ. 2003. Replication protein A-mediated recruitment and activation of Rad17 complexes. Proc Natl Acad Sci 100: 13827-13832. 


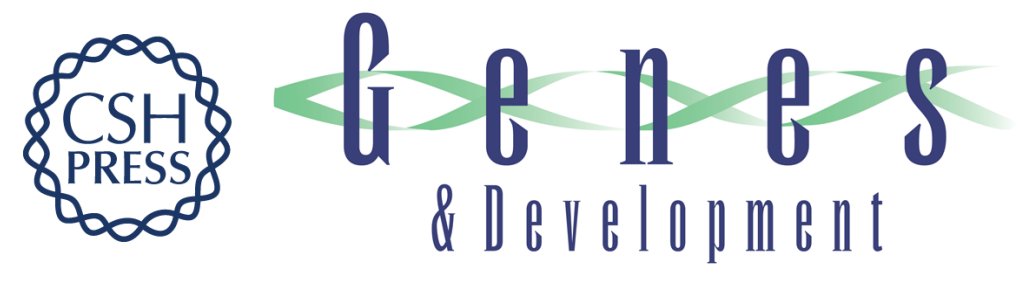

\title{
The SIOD disorder protein SMARCAL1 is an RPA-interacting protein involved in replication fork restart
}

\author{
Alberto Ciccia, Andrea L. Bredemeyer, Mathew E. Sowa, et al. \\ Genes Dev. 2009, 23: originally published online September 30, 2009 \\ Access the most recent version at doi:10.1101/gad.1832309
}

\section{Supplemental http://genesdev.cshlp.org/content/suppl/2009/09/23/gad.1832309.DC1 \\ Material}

Related Content

References

\section{License}

Email Alerting Service
HARPing on about the DNA damage response during replication Robert Driscoll and Karlene A. Cimprich

Genes Dev. October, 2009 23: 2359-2365 The annealing helicase SMARCAL1

maintains genome integrity at stalled replication forks

Carol E. Bansbach, Rémy Bétous, Courtney A. Lovejoy, et al.

Genes Dev. October , 2009 23: 2405-2414 The annealing helicase HARP protects

stalled replication forks

Jingsong Yuan, Gargi Ghosal and Junjie Chen

Genes Dev. October , 2009 23: 2394-2399 The annealing helicase HARP is recruited

to DNA repair sites via an interaction with RPA

Timur Yusufzai, Xiangduo Kong, Kyoko Yokomori, et al.

Genes Dev. October, 2009 23: 2400-2404

This article cites 36 articles, 11 of which can be accessed free at:

http://genesdev.cshlp.org/content/23/20/2415.full.html\#ref-list-1

Articles cited in:

http://genesdev.cshlp.org/content/23/20/2415.full.html\#related-urls

Receive free email alerts when new articles cite this article - sign up in the box at the top right corner of the article or click here.

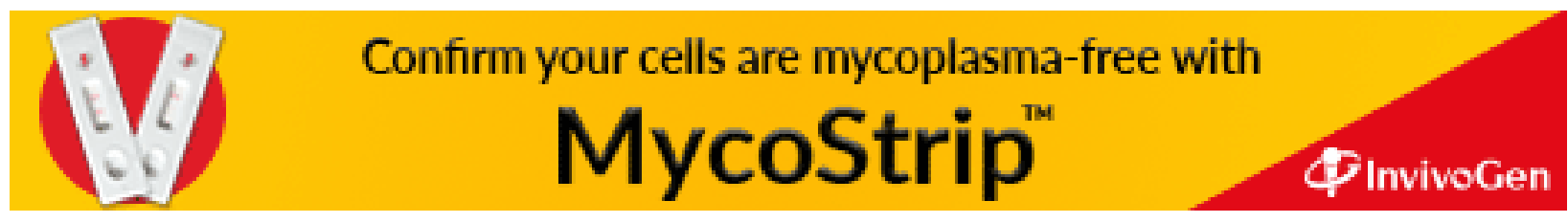

